\title{
EXTRAÇÃO VIA FLUIDO SUPERCRÍTICO DE COMPOSTOS DE ALTO VALOR COMERCIAL DE Spirulina platensis
}

\author{
D. FILÓCOMO ${ }^{1}$, V. C. N. SANTANA ${ }^{2}$, P. C. N. TEIXEIRA ${ }^{3}$ e G.L.V. COELHO ${ }^{4}$ \\ ${ }^{1,2,4}$ Universidade Federal Rural do Rio de Janeiro , Departamento de Engenharia Química. \\ ${ }^{3}$ Instituto Nacional de Tecnologia , Divisão de Energia. \\ E-mail para contato: diegofilocomo@ hotmail.com
}

\begin{abstract}
RESUMO - Este trabalho teve como objetivo a avaliação preliminar de duas condições de extração de clorofila-a e carotenoides provenientes da biomassa de Spirulina platensis através da extração via fluido supercrítico. A extração foi conduzida sob as condições de temperatura de 40 e $60{ }^{\circ} \mathrm{C}$, pressão de 150 e 180 bar, e granulometria da amostra de 48 mesh. Os compostos obtidos foram avaliados por técnica espectrofotométrica e comparados com aqueles obtidos via extração por solvente convencional utilizando acetona $90 \%$, de modo a se avaliar a eficiência do método empregado. Os resultados obtidos mostraram que a extração supercrítica apresentou maior seletividade na extração da clorofila-a, e que esta foi favorecida à medida que se aumentou a pressão e temperatura. Já o método de extração com acetona 90\% apresentou maior seletividade na extração de carotenoides totais, apresentando concentração de $1,6 \mathrm{mg} / \mathrm{L}^{-1}$ enquanto que para a clorofila-a, o valor alcançado foi de $0,1 \mathrm{mg} / \mathrm{L}^{-1}$.
\end{abstract}

\section{INTRODUÇÃO}

Microalgas são organismos unicelulares caracterizados pela sua capacidade fotossintética, processo em que a energia solar é convertida em energia química. Quanto à sua composição, a presença de diversos compostos de alto valor comercial tem despertado cada vez mais interesse, devido à aplicabilidade destes nos mais diversos tipos de segmentos (Vonshak, 1990). Em especial as microalgas do gênero Spirulina sp, têm mostrado um grande potencial conferido por seu alto valor nutricional (Belay, 2002), através da elevada síntese de proteínas (Ciferri \& Tiboni, 1985), aminoácidos essenciais (Tanticharoen et. al., 1994), $\beta$ caroteno e vitaminas, inclusive a vitamina $\mathrm{B}_{12}$ (Vonshak \& Richmond, 1988). Além disso, essas cianobactérias apresentam uma série de propriedades terapêuticas: aumentam a eficiência do sistema imune em animais (Qureshi et. al., 1996; Al-Batshan et. al., 2001), reduzem a hipercolesterolemia (Hosoyamada et. al., 1991; Rammamoorthy \& Premakumari, 1996) e atuam como antivirais (Hayashi et. al., 1996) e antitumorais (Liu et. al., 2000). Aliado a essas qualidades nutricionais e terapêuticas, a Spirulina também produz compostos de alto valor comercial, tais como a ficocianina, o ácido $\gamma$-linolênico (ômega 6) (Cohen et. al., 1993), o $\beta$-caroteno e a clorofila.

Como alternativa para a extração destes valiosos compostos, destaca-se o processo de extração supercrítica (SFE), considerado uma técnica sustentável por não fazer uso de solventes danosos ao meio ambiente, além de ser uma técnica de execução relativamente 
rápida e mais limpa, do ponto de vista ambiental, se comparada aos métodos de extração convencionais com solventes. Aliado a isso, tem-se o alto poder de seletividade associado à extração dos compostos, o que torna viável e eficiente a utilização deste método para a extração.

O processo de extração supercrítico utiliza como solvente, um fluido à temperatura e pressão acima do ponto crítico. Nestas condições é possível formar uma fase, com o fluido apresentando a compressibilidade de um gás e a densidade de um líquido (Sawangkeaw, Bunyakiat \& Ngamprasertsith, 2010). Em condições supercríticas, a densidade pode ser alterada com pequenas variações de temperatura e/ou pressão (Carrilho et. al., 2001).

O dióxido de carbono é o solvente mais utilizado neste processo de extração, pois possui características que tornam este processo interessante para indústria de alimentos (Meireles, 1997), como: nula toxicidade, fácil obtenção atingindo altos níveis de pureza, não inflamável, inércia química em relação à matéria prima, baixa temperatura crítica $\left(31,2^{\circ} \mathrm{C}\right)$ e moderada pressão crítica (73,4 bar). Diante do exposto, o presente estudo pretende avaliar através de técnica espectrofotométrica, ainda que de forma preliminar, a eficiência da extração por fluido supercrítico da clorofila-a e de carotenoides, de uma biomassa de Spirulina platensis.

\section{MATERIAIS E MÉTODOS}

Os experimentos foram realizados na unidade de extração do Laboratório de Processos de Separação (LPS), Figura 1. O solvente utilizado foi o dióxido de carbono $\mathrm{CO}_{2} \mathrm{em}$ condições supercríticas.

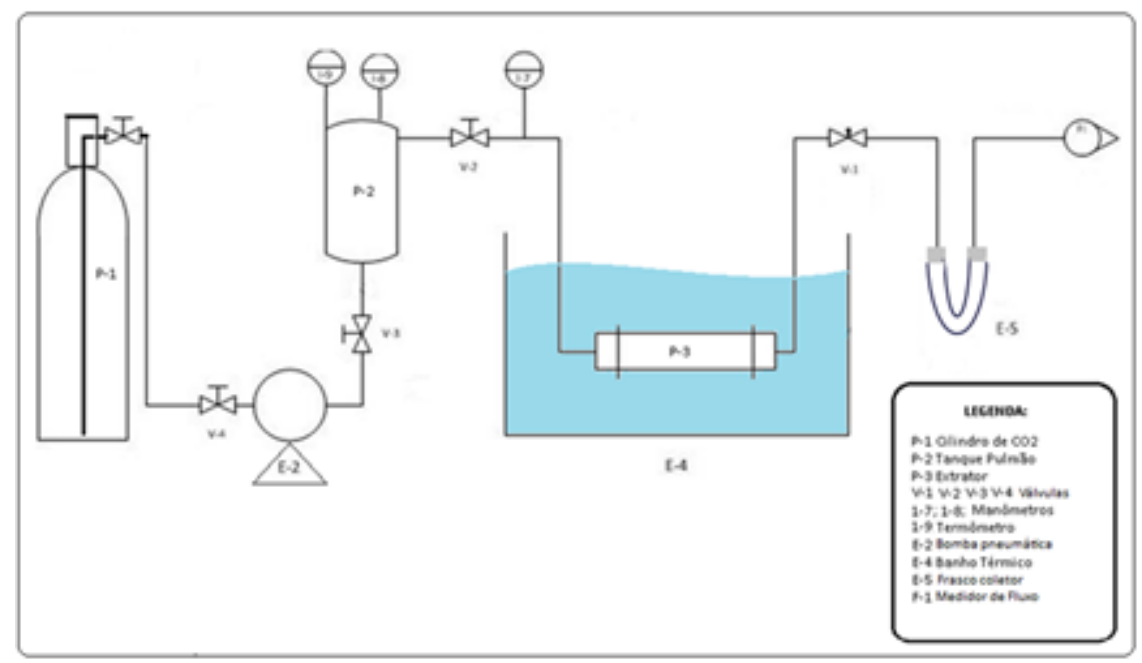

Figura 1 - Esquema ilustrativo da unidade de extração supercrítica do LPS - UFRRJ.

Primeiramente, a biomassa seca da microalga Spirulina platensis, foi moída e posteriormente, peneirada em peneira de 48 mesh, para garantir a homogeneidade da amostra. 
Foi utilizado um extrator com capacidade de $2,67 \mathrm{ml}$ tendo em média $0,8 \mathrm{~g}$ de biomassa empacotada. $\mathrm{O}$ leito formado teve as suas extremidades preenchidas com uma camada de 0,5 $\mathrm{cm}$ de micro esferas de vidro com tamanho de 10 mesh.

Posteriormente, a unidade de extração foi ajustada dentro dos parâmetros desejados conforme a Tabela 1. Após o tempo de estabilização de 1 hora, foi ajustada a vazão mássica por meio de uma válvula micrométrica e um bolhômetro manual acoplados ao final da linha de extração.

Tabela 1 - Condições experimentais durante o processo de extração supercrítica

\begin{tabular}{|c|c|c|c|}
\hline Experimento & Vazão mássica $(\mathrm{L} / \mathrm{h})$ & Pressão (bar) & Temperatura $\left({ }^{\circ} \mathrm{C}\right)$ \\
\hline 01 & 2 & 150 & 40 \\
\hline 02 & 20 & 180 & 60 \\
\hline
\end{tabular}

O período de duração das extrações foi de $4 \mathrm{~h}$ e para a recolha dos extratos foi utilizado um tubo de vidro em formato de "U" conectado à válvula de expansão, conforme mostra a Figura 1.

Durante o processo, o tubo em "U" permaneceu revestido com papel alumínio para garantir a preservação dos pigmentos extraídos. Após o término da extração, o tubo em "U" foi lavado com $10 \mathrm{ml}$ de acetona $90 \%$ para recolher o extrato. Da solução de lavagem do tubo, foram separados 2,6 ml para a leitura imediata em espectrofotômetro e avaliação do conteúdo de carotenoides totais e clorofila-a através das equações 1 e 2 , respectivamente.

Carotenoides totais $\left(\mu \mathrm{g} \mathrm{L}^{-1}\right)=\left[7,6 \times A_{480 \mathrm{~nm}}-\left(3,0 \times A_{750 \mathrm{~nm}}\right)-1,49 \times A_{510 \mathrm{~nm}}-(2,0 \times\right.$ $\left.\left.A_{750 \mathrm{~nm}}\right)\right] \times v /(V \times c)$

Clorofila-a $\left(\mu g L^{-1}\right)=\left[11,85 \times A_{664 n m}-1,54 \times A_{647 n m}-0,08 \times A_{630 n m}\right] \times v /(V \times c)$

Extrações de carotenóides e clorofila-a com acetona $90 \%$ foram realizadas seguindo o protocolo descrito por Strickland \& Parson (1968), como um método comparativo em relação a extração supercrítica. Neste protocolo, biomassa seca e granulada de Spirulina foi reduzida a um pó bem fino com o auxilio de um grau e uma peneira de pequena gramatura.

Uma porção de $0,4 \mathrm{~g}$ deste pó fino de biomassa foi reservada e sobre ela adicionado $500 \mathrm{ml}$ de água destilada, para promover a ressuspensão da biomassa. Após a obtenção dos extratos, foram feitas leituras em espectrofotômetro nos comprimentos de onda de 480, 510 e 
$750 \mathrm{~nm}$ para quantificação dos carotenóides totais e 630,647, 664, e $750 \mathrm{~nm}$ para a quantificação da clorofila-a. Tanto os dados da extração via fluído supercrítico quanto os dados obtidos a partir da extração com acetona $90 \%$ foram trabalhados e plotados com o auxilio do programa ORIGIN PRO 8.0.

\section{RESULTADOS}

A partir dos processos de extração de pigmentos via fluído supercrítico, via solvente convencional (acetona 90\%) e das avaliações via técnicas de espectrofotometria foram gerados o Gráfico 1, representando as condições sob as quais foram conduzidos os experimentos de extração supercrítica e a concentração dos extratos obtidos através das duas metodologias; o Gráfico 2 representando os dados de uma análise de varredura espectrofotométrica na faixa entre 400 e $750 \mathrm{~nm}$ do extrato obtido via extração com acetona $90 \%$, e o Gráfico 3 representando uma análise de varredura espectrofotométrica na faixa entre 400 e 750nm, feita a partir do filtrado que foi gerado no processo de filtração por membrana após a ressuspensão, em água destilada, da biomassa e seca triturada.

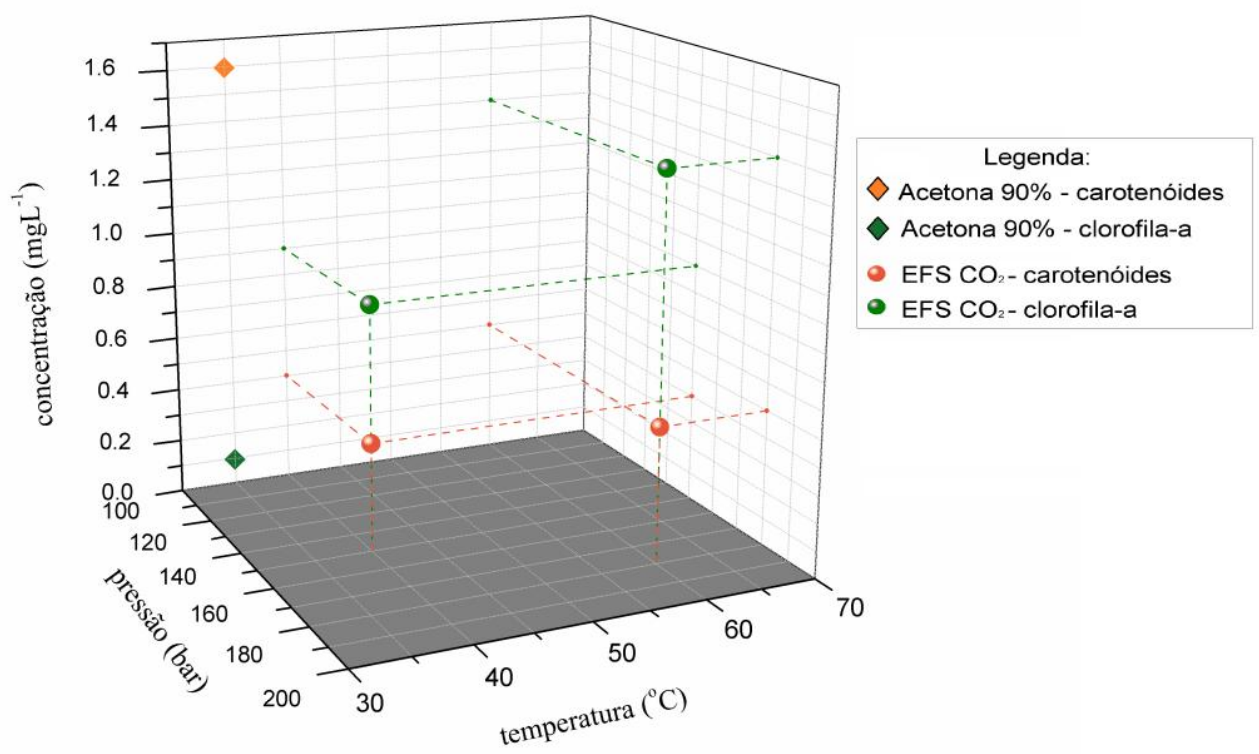

Gráfico 1 - Condições de extração supercrítica, resultados obtidos após 4h de extração e representação dos resultados obtidos via extração com acetona $90 \%$. 


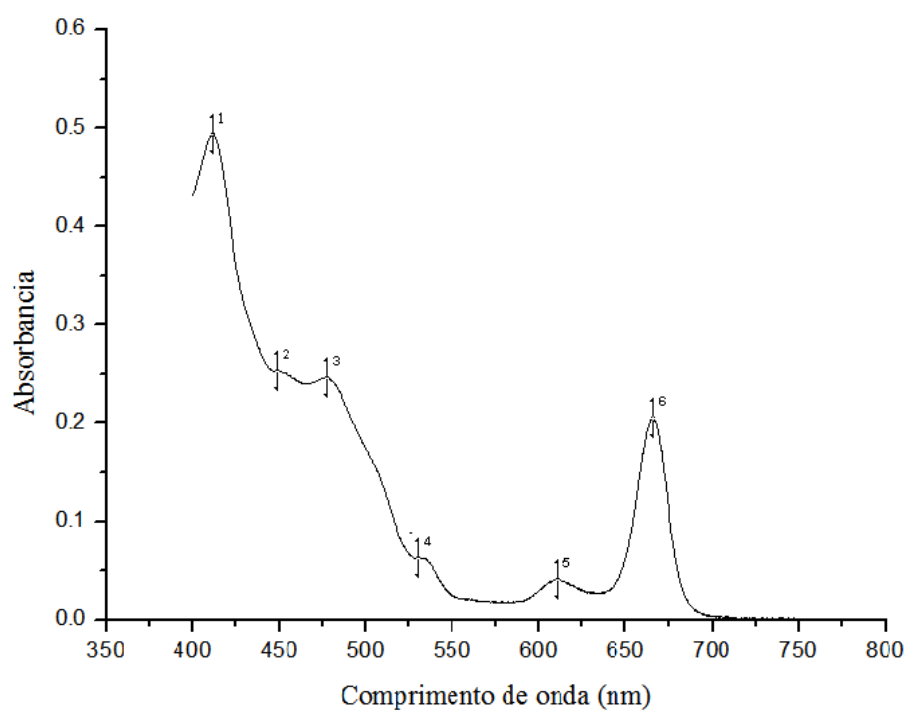

Gráfico 2 - Varredura do extrato obtido através da extração com acetona 90\%. Picos característicos de carotenóides: 2 e 3. Picos característicos da clorofila-a: 1, 4, e 6. Pico característico da ficocianina: 5.

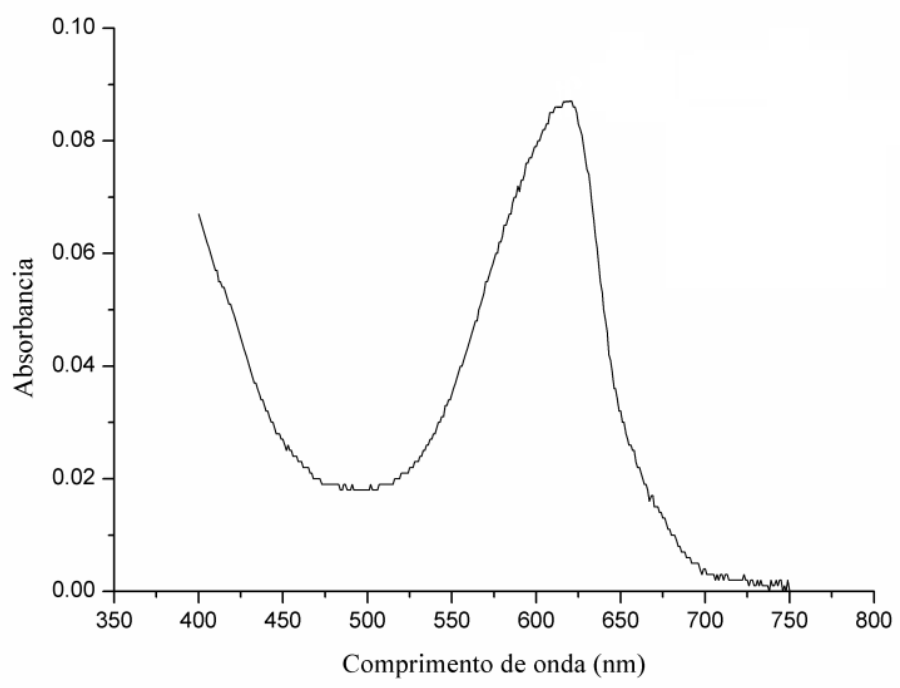

Gráfico 3 - Varredura do material filtrado para extração após a ressuspensão em água destilada. Pico característico da ficocianina.

\section{DISCUSSÃO}

Ao avaliarmos o Gráfico 1, podemos perceber que a extração conduzida sob pressão de 150 bar e $40^{\circ} \mathrm{C}$ apresentou menores valores de concentração dos pigmentos desejados quando comparada a extração realizada sob pressão de 180 bar e $60^{\circ} \mathrm{C}$. Este gráfico também nos 
permite dizer que as condições supercríticas testadas, foram mais eficientes na solubilização da clorofila-a do que na dos carotenóides, este fato pode estar relacionado com a diferença de solubilidade entre os compostos, uma vez que a literatura aponta pressões entre 200 e $300 \mathrm{bar}$ como sendo favoráveis à solubilidade dos carotenoides.

Ainda neste gráfico, fica notório que o método de extração por solventes convencionais utilizando acetona $90 \%$ tem alta seletividade de extração para carotenóides, apresentando como valores de concentração de carotenóides totais de $1,6 \mathrm{mg} / \mathrm{L}^{-1}$ enquanto que para clorofila-a os valores ficam restritos a $0,1 \mathrm{mg} / \mathrm{L}^{-1}$. Esta seletividade fica clara quando olhamos para o Gráfico 2 e verificamos que apesar da biomassa apresentar-se rica em clorofila-a, após a extração por acetona, os resultados de concentração de carotenóides totais foram muito superiores aos de clorofila-a.

Após a filtração com membrana, da biomassa ressuspensa em água destilada, o filtrado apresentou uma coloração azulada. Uma análise espectrofotométrica foi realizada e o resultado está apresentado no Gráfico 3, evidenciando espectralmente a presença de pico característico da ficocianina, que provavelmente, devido a sua característica hidrofílica, após o processo de trituração e ressuspensão da amostra em água destilada, foi extraída

\section{CONCLUSÃO}

Os resultados obtidos mostram que a extração supercrítica apresentou maior seletividade na extração da clorofila-a, e que esta foi favorecida à medida que se aumentou a pressão e temperatura, diferentemente do método de extração com acetona $90 \%$, que apresentou maior seletividade na extração de carotenoides totais. No entanto, novos experimentos devem ser realizados com o objetivo de avaliar o rendimento do processo de extração supercrítica em diferentes condições, já que a literatura indica que carotenoides apresentam maior solubilidade em temperaturas e pressões mais elevadas.

\section{NOMENCLATURA}

$\mathrm{A}_{480 \mathrm{~nm}}=$ Absorbância com comprimento de onda de 480nm

$\mathrm{A}_{510 \mathrm{~nm}}=$ Absorbância com comprimento de onda de 520nm

$\mathrm{A}_{630 \mathrm{~nm}}=$ Absorbância com comprimento de onda de 630nm

$\mathrm{A}_{647 \mathrm{~nm}}=$ Absorbância com comprimento de onda de $647 \mathrm{~nm}$

$\mathrm{A}_{664 \mathrm{~nm}}=$ Absorbância com comprimento de onda de 664nm

$\mathrm{c}=$ Caminho óptico da cubeta

$\mathrm{v}=$ Volume de solvente utilizado para a extração dos pigmentos

$\mathrm{V}=$ Volume filtrado de amostra 


\section{REFERÊNCIAS}

AL-BATSHAN, H. A.; AL-MUFARREJ, S. I.; AL-HOMAIDA, A. A.; QURESHI, M. A. Enhancement of chicken macrophage phagocytic function and nitrite production by dietary Spirulina platensis. Immunopharmacol Immunotoxicol., v. 23, p. 281-289, 2001.

BELAY, A. The potential of Spirulina (Arthrospira) as a nutricional and therapeutic supplement in health management. J. Amer. Nutraceutical Association, v. 5, p. 27-48, 2002.

CARRILHO, E. Fluidos Supercríticos Em Química Analítica. I. Cromatografia Com Fluido Supercrítico:Conceitos Termodinâmicos. Química Nova, v. 24, p. 509-515, 2001.

CIFERRI, O.; TIBONI, O. The biochemistry and industrial potential of Spirulina. Ann. Rev. Microbiol., v. 39, p. 503-526, 1985.

COHEN, Z.; REUNGJITCHACHAWALI, M.; SIANGDUNG, W.; TANTICHOROEN, M. Production and partial purification of $\gamma$-linolenic acids and some pigments from Spirulina platensis. J. Appl. Phycol., v. 5, p. 109-115, 1993.

HAYASHI, K.; HAYASHI, T.; KOJIMA, I. A natural sulfated polysaccharide, calcium spirulan, isolated from Spirulina platensis: in vivo and ex vivo evaluation of anti-Herpes simples virus and anti-human immunodeficiency virus activities. AIDS Research and Human Retroviruses, v. 12, p. 1463-1471, 1996.

HOSOYAMADA, Y.; TAKAI, T.; KATO, T. Effects of water-soluble and insoluble fractions of Spirulina on serum lipid components and glucose tolerance in rat. J. Jpn Soc. Nutr. Food Sci., v., 44, p. 273-277, 1991.

LAWS, E. A.; TERRY, K. L. ; WICKMAN, J.; CHALUP, M. S. Simple algal production system design to utilize the flashing light effect. Biotechnol. Bioeng, v. 25, p. 2319-2336, 1983.

LIU, Y.; XU, L.; CHENG, N.; LIN, L.; ZHANG, C. Inhibitory effect of phycocyanin from Spirulina platensis on the growth of human leukemia K562 cell- J. Appl. Phycol., v. 12, p. 125-130, 2000.

MEIRELES, M. A. A. Extração supercrítica de óleos essenciais de condimentos usando dióxido de carbono. Boletim da SBCTA, v. 31, p. 9-14, 1997.

MOLINA GRIMA, E.; ACIÉN FERNANDEZ, F. G.; GARCIA CAMACHO, F.; CHISTI, Y. Photobioreactors: light regime, mass transfer, and scaleup. J. Biotechnol.,_v. 70, p. 231-247, 1999.

MORITA, M.; WATANABE, Y.; SAIKI, H. Investigation of photobioreactor design for enhancing the photosynthetic productivity of microalgae. Biotechnol. Bioeng., v. 69, p. 693698, 2000. 
PULZ, O. Photobioreactors: production systems for phototrophic microorganisms. Appl. Microbiol. Biotechnol., v. 57, p. 287-293, 2001.

QURESHI, M. A.; GARLICH, J. D.; KIDD, M. T. Dietary Spirulina platensis enhances humoral and cell-mediated immune functions in chickens. Immunopharmacol Immunotoxicol., v. 18, p. 465-76, 1996.

RAMAMOORTHY, A.; PREKUMARI, S. Effect of supplementation of Spirulina on hypercholesterolemic patients. J. Food Sci. Technol., v. 33, p. 124-128, 1996.

SAWANGKEAW, R.; BUNYAKIAT, K. \& NGAMPRASERTSITH S. A review of laboratory-scale research on lipid conversion to biodiesel with supercritical methanol (20012009). J. of Supercritical Fluids., v. 55, p. 1-13, 2010.

TANTICHAROEN, M.; REUNGJITCHACHAWALI, M.; BUNNAG, B.; VONKTAVEESUK, P.; VONSHAK, A.; COHEN, Z. Optimization of $\gamma$-linolenic acid (GLA) production in Spirulina platensis. J. Appl. Phycol., v. 6, p. 295-300, 1994.

TERRY, K; RAYMOND, L. P. System design for the autotrophic production of microalgae. Enzyme Microb. Technol., v. 7, p. 474-487, 1985.

VONSHAK, A. Recent advances in microbial biotechnology. Biotech. Adv., v. 8, p. 709-727, 1990.

VONSHAK, A.; Richmond, A. Mass production of Spirulina- an overview. Biomass., v. 15, p. 233-248, 1988.

YOSHIDA, A.; TAKAGAKI, Y.; NISHIMUNE, T. Enzyme immunoassay for phycocyanin as the main component of spirulina color in foods. Biosci Biotechnol. Biochem., v. 60, p. 5760, 1996. 